\title{
Prognostic indicators of cardiovascular risk in renal disease
}

\author{
Cara M. Hildreth* \\ Australian School of Advanced Medicine, Macquarie University, Sydney, NSW, Australia
}

\section{Edited by:}

Elisabeth Lambert, Baker IDI Heart and Diabetes Institute, Australia

Reviewed by:

Gavin W. Lambert, Baker IDI Heart and Diabetes Institute, Australia

Tom Cunningham, University of North

Texas Health Science Center, USA

${ }^{*}$ Correspondence:

Cara M. Hildreth, Australian School of Advanced Medicine, Macquarie University, Sydney, NSW 2109,

Australia.

e-mail: cara.hildreth@mq.edu.au
Although the annual mortality rate for end-stage renal disease (ESRD) is decreasing, likely due to an increase in kidney transplantation rate, the survival probability for ESRD patients from day one of dialysis has not changed, and is still poor with a 5-year survival rate of approximately $34 \%$. This is contributed to by a high prevalence of cardiovascular disease, which is the leading cause of death in ESRD patients. In order to improve survival outcomes, patients at high risk of cardiovascular related mortality need to be identified. Heart rate variability (HRV), baroreceptor sensitivity, and baroreceptor reflex effectiveness index can be used to assess heart rate control and may predict cardiovascular mortality. This paper will discuss how HRV, baroreceptor sensitivity, and baroreceptor reflex effectiveness index are altered in renal disease and the utility of these indices as markers of cardiac risk in this patient population.

Keywords: baroreceptor reflex sensitivity, heart rate variability, end-stage renal disease

\section{INTRODUCTION}

Cardiovascular disease is highly prevalent chronic kidney disease (CKD) and end-stage renal disease (ESRD) patients, and occurs due to the development of vasculopathies, e.g., atherosclerosis or arteriosclerosis, or cardiomyopathy, resulting in ischemic heart disease or heart failure (Parfrey and Foley, 1999; Shamseddin and Parfrey, 2011). The high incidence of cardiovascular disease in CKD/ESRD patients is due to a greater prevalence of traditional cardiovascular risk factors, e.g., hypertension, hyperlipidemia, and diabetes, and risk factors associated with a chronic uremic state, e.g., volume overload, anemia, and oxidative stress (Parfrey and Foley, 1999). Consequently, cardiovascular disease is the leading cause of death in ESRD patients, accounting for $\sim 40 \%$ of deaths in dialysis patients (U.S. Renal Data System, 2011).

Sudden cardiac death is the major cause of cardiac mortality in ESRD (Herzog, 2003; U.S. Renal Data System, 2011). The incidence of sudden cardiac death increases as the stage of kidney disease increases. In a retrospective study of renal disease patients with coronary artery disease, the incidence of sudden cardiac death was 3.8 events per 1000 patient-years in patients with an estimated glomerular filtration rate (eGFR) $\geq 60 \mathrm{ml} / \mathrm{min}, 7.3 \mathrm{in}$ patients with an eGFR between $15-59 \mathrm{ml} / \mathrm{min}$, and 24.2 in dialysis patients (Pun et al., 2009). The prognosis for ESRD patients who have been resuscitated following a cardiac arrest is abysmal, with $60 \%$ of patients dying in the first 48-h (Karnik et al., 2001), and a 30 -day and 1-year survival rate of only 32 and $15 \%$, respectively (Herzog, 2003). Nevertheless, despite these disturbing statistics, the high cardiovascular mortality rate in ESRD patients may be reduced, as the use of angiotensin converting enzyme inhibitors or angiotensin receptor blockers, independent of any antihypertensive effect, is associated with a lower risk of mortality (Efrati et al., 2002; Fang et al., 2008). In order to reduce the cardiac mortality rate in ESRD, however, CKD or ESRD patients at a high risk of cardiac death need to be identified early, to allow appropriate clinical intervention.
Abnormalities in autonomic function, namely sympathetic overdrive and parasympathetic insufficiency, play a key role in the susceptibility to sudden cardiac death (Schwartz and Stone, 1980; Schwartz et al., 1988, 1992). There is now an overwhelming amount of evidence showing the involvement of the autonomic nervous system in the genesis of cardiovascular disease in CKD. This includes sympathetic overactivity, as muscle (Converse et al., 1992; Hausberg et al., 2002; Klein et al., 2003), but not skin (Park et al., 2008; Grassi et al., 2009), sympathetic nerve activity is elevated. The increase in muscle sympathetic nerve activity occurs early in the disease progression (Grassi et al., 2011) and likely increases the risk of mortality, as elevated plasma noradrenaline levels are associated with both an increased risk of all-cause mortality and cardiovascular events in ESRD patients without heart failure (Zoccali et al., 2002). Conversely, parasympathetic nerve activity is reduced, evidenced by reduced heart rate (HR) responses to deep breathing, valsalva maneuver, and standing up (Agarwal et al., 1991; Sahin et al., 2006). This sympatho-vagal imbalance undoubtedly contributes to the increased risk of sudden cardiac death in CKD/ESRD.

Heart rate variability (HRV) and baroreceptor reflex sensitivity (BRS) can be used to examine autonomic regulation of HR. In myocardial infarction survivors, reduced HRV and BRS have been shown to be highly predictive of an increased risk of cardiac mortality (La Rovere et al., 1998, 2001). This review will discuss how HRV, BRS, and an additional measure of baroreflex function, baroreceptor effectiveness index (BEI), are altered in renal disease, and their utility in predicting cardiac risk in ESRD patients.

\section{HEART RATE VARIABILITY}

Heart rate variability reflects the ability of the sinoatrial node to adaptively alter HR in response to sympathetic and parasympathetic inputs, respiration, circadian rhythm, and hormonal and thermoregulatory influences (Stauss, 2003). In many disease states, the sinoatrial node is less able to alter HR, and instead the heart beats like a metronome. Irrespective of the underlying cause, a 
reduction in HRV may predict sudden cardiac death (Molgaard et al., 1991; La Rovere et al., 2003; Kataoka et al., 2004).

Heart rate variability can be assessed in a variety of ways: timedomain analysis (statistical or geometrical), frequency-domain analysis, or non-linear methods (Task Force of the ESC and NASPE, 1996). Statistical time- and frequency-domain analyses of HRV are the most commonly used methods. Statistical timedomain parameters of $\mathrm{HRV}$ include $\mathrm{SD}$ of all normal $\mathrm{R}-\mathrm{R}$ intervals (SDNN), SD of the average R-R interval in all 5-min segments (SDANN), square root of the mean squared differences of successive $\mathrm{R}-\mathrm{R}$ intervals (RMSDD), and the proportion of adjacent $\mathrm{R}-\mathrm{R}$ intervals that are more than $50 \mathrm{~ms}$ apart (pNN50). Frequencydomain indices of HRV include total (TP), high frequency (HF), low frequency (LF), and very low frequency (VLF) power. Total power and SDNN correlate, reflecting overall HRV. HF power, RMSDD, and pNN50 are analogous and reflect vagal and respiratory mediated changes in HR. LF power reflects the capacity of both the parasympathetic and sympathetic nervous systems to alter HR, and cardiovascular reflexes, such as the, baroreceptor reflex to buffer changes in HR. VLF and SDANN reflect long-term changes in HR (Task Force of the ESC and NASPE, 1996; Zaza and Lombardi, 2001; Guzik et al., 2007). A summary of how the various HRV indices are altered in CKD/ESRD is presented in Table 1.

The Renal Research Institute-CKD study, a four center prospective cohort study of adults with moderate to severe CKD (stages $3-5$ ), demonstrated that $\mathrm{HRV}$ decreased as renal disease severity increased. In this study, SDNN, SDANN, VLF, and LF:HF power was lower in stage 5 non-dialysis CKD patients compared with stage 3 and 4 CKD patients (Chandra et al., 2011). Furthermore, in type 1 diabetics with overt nephropathy, SDNN, RMSSD, pNN50, SDANN, and LF power are positively related to creatinine clearance, such that a decline in creatinine clearance is associated with a diminution of HRV (Burger et al., 2002). Thus, the progressive decline in renal function that occurs in renal disease alters autonomic and long-term regulation of $\mathrm{HR}$, resulting in a reduction in HRV.

Few studies have examined the difference in HRV parameters between stage $4 / 5$ non-dialysis CKD and dialysis patients. Those that have demonstrate no difference in the spectral indices (i.e., TP, HF, and LF) between stage 4/5 non-dialysis CKD and dialysis patients (Mylonopoulou et al., 2010; Roumelioti et al., 2010), while time-domain indices (e.g., SDNN and SDANN) may increase in dialysis patients (Mylonopoulou et al., 2010). The lack of difference in spectral HRV indices may indicate that the inhibitory effect of renal disease on HRV has reached maximal levels prior to the need for renal replacement therapy.

Several co-variates affect HRV estimates in ESRD/CKD patients, the most significant of which is diabetes. Regardless of disease stage, diabetic CKD patients have lower HRV indices (Yamanaka et al., 2005; Mylonopoulou et al., 2010; Chandra et al., 2011). The combination of renal disease and diabetes has a greater inhibitory effect on HRV than the presence of renal disease or diabetes alone, with non-diabetic ESRD and diabetic patients having similar HRV estimates (Mylonopoulou et al., 2010). The only exception is HF power, which is comparable in diabetic and nondiabetic ESRD patients (Mylonopoulou et al., 2010). High resting
HR, older age, elevated serum phosphorus levels, anemia, high cholesterol levels, increased left ventricular mass index, and/or use of beta-blockers are also associated with reduced HRV in CKD and ESRD (Steinberg et al., 1998; Furuland et al., 2008; Chandra et al., 2011).

One of the hypothesized causes for autonomic dysfunction, which can result in reduced HRV and an increased risk of cardiac mortality (La Rovere et al., 1998), in ESRD is a uremia driven excitation of the renal afferent nerves. Accordingly, muscle sympathetic nerve activity is lower in nephrectomized versus nonnephrectomized ESRD patients (Converse et al., 1992). Furthermore, conversion from conventional to nocturnal hemodialysis, which allows for a more aggressive correction of uremia, reduces plasma noradrenaline levels (Chan et al., 2003). Uremic excitation of renal afferents may also underlie reduced HRV. Acutely, hemodialysis increases SDNN, SDANN and reduces the ratio of LF to HF power (Giordano et al., 2001; Tong and Hou, 2007; Mylonopoulou et al., 2010; Celik et al., 2011); whereas, conversion from chronic to nocturnal hemodialysis increases HF power and normalizes LF to HF ratio (Chan et al., 2004). Following renal transplantation, there is an eventual improvement in HRV. At 1 month post-transplantation, HRV parameters are similar to pre-transplantation levels (Yang et al., 2010), while from 5 to 12 months post-transplantation, LF, HF, TP, and SDNN are similar to healthy control levels (Yildiz et al., 1998; Rubinger et al., 2009; Yang et al., 2010). Nevertheless, such improvements are not always reported (Kurata et al., 2004; Parisotto et al., 2008); whether this reflects an insufficient post-surgical recovery time (recovery time $1-4+$ months) or other causes for reduced HRV in ESRD is unknown.

The Renal Research Institute-CKD study concluded that a low LF to HF ratio was associated with a higher risk of progression to ESRD (Chandra et al., 2011) and the Atherosclerosis Risk in Communities study highlighted the association between low LF and HF power and the subsequent development of renal impairment, even after correction for classical risk factors such as diabetes, hypertension, and low baseline renal function (Brotman et al., 2010). On the basis of this alone, reduced HRV values are predictive of a greater risk of mortality, whether cardiac related or not, due to a higher risk of developing ESRD. Reduced HRV can also predict an increased risk of cardiac mortality, with retrospective evidence existing that ESRD or CKD patients that died of coronary artery disease, peripheral artery disease, congestive heart failure, acute myocardial infarction, or a cardiac arrest, had reduced HRV, notably low VLF, LF, and LF to HF ratio values, compared with survivors (Fukuta et al., 2003a; Chandra et al., 2011). Interestingly, ultra LF power, a rarely reported frequencydomain parameter that reflects circadian rhythm changes in HR (Stauss, 2003), is a highly sensitive parameter in predicting cardiac related deaths (e.g., acute myocardial infarction, heart failure, sudden cardiac death) in ESRD patients (Hayano et al., 1999; Fukuta et al., 2003a,b), with values less than $8.7 \mathrm{~ms}^{2}$, predictive of sudden cardiac death (Hayano et al., 1999). Time-domain estimates of HRV are also predictive of cardiac mortality, with SDNN estimates less than $50 \mathrm{~ms}$ reflective of a greater risk of sudden cardiac death (Hathaway et al., 1998; Hayano et al., 1999). 
Table 1 | Heart rate variability parameters in end-stage renal disease patients.

\begin{tabular}{|c|c|c|c|}
\hline Reference & Patient cohort & $\begin{array}{l}\text { HRV parameters } \\
\text { in ESRD patients }\end{array}$ & Comments \\
\hline Celik et al. (2011) & $\begin{array}{l}31 \text { ESRD patients on HD therapy } \\
31 \text { Healthy controls }\end{array}$ & $\begin{array}{l}\text { Reduced SDNN } \\
\text { Reduced SDANN } \\
\text { Reduced RMSSD }\end{array}$ & $\begin{array}{l}\text { Comparisons made with controls only following dialy- } \\
\text { sis therapy } \\
\text { Showed that HRV parameters improved following HD } \\
\text { therapy }\end{array}$ \\
\hline Yang et al. (2010) & $\begin{array}{l}14 \text { ESRD patients on HD therapy } \\
14 \text { Healthy controls }\end{array}$ & $\begin{array}{l}\text { Reduced total power } \\
\text { Reduced LF power } \\
\text { Reduced HF power }\end{array}$ & $\begin{array}{l}\text { Showed that all HRV parameters had improved by } 6 \\
\text { months following renal transplantation }\end{array}$ \\
\hline Giordano et al. (2001) & $\begin{array}{l}20 \text { ESRD patients ( } 9 \text { diabetic) on HD } \\
\text { therapy } \\
10 \text { Healthy controls }\end{array}$ & $\begin{array}{l}\text { Reduced total power } \\
\text { Increased LF (nu) } \\
\text { Reduced HF (nu) }\end{array}$ & $\begin{array}{l}\text { Results shown here only include non-diabetic ESRD } \\
\text { patients } \\
\text { Total power and HF power lower in diabetic ESRD } \\
\text { patients } \\
\text { LF power higher in diabetic ESRD patients }\end{array}$ \\
\hline Kurata et al. (2004) & $\begin{array}{l}13 \text { ESRD patients on HD patients } \\
10 \text { Healthy controls }\end{array}$ & $\begin{array}{l}\text { Reduced SDNN } \\
\text { Reduced rMSSD } \\
\text { Reduced LF power } \\
\text { Reduced HF power }\end{array}$ & $\begin{array}{l}\text { Renal transplantation had no effect on HRV } \\
\text { parameters measured }\end{array}$ \\
\hline Yang et al. (2010) & $\begin{array}{l}14 \text { ESRD patients on HD that received } \\
\text { renal transplants } \\
14 \text { Healthy controls }\end{array}$ & $\begin{array}{l}\text { Reduced total power } \\
\text { Reduced LF power } \\
\text { Reduced HF power }\end{array}$ & $\begin{array}{l}\text { Renal transplant normalized reduction in total power } \\
\text { Renal transplant increased but did not normalize, LF } \\
\text { and HF power }\end{array}$ \\
\hline Fukuta et al. (2003a) & $\begin{array}{l}120 \text { ESRD patients on HD therapy } \\
62 \text { Healthy controls }\end{array}$ & $\begin{array}{l}\text { Reduced SDNN } \\
\text { Reduced total power } \\
\text { Reduced ULF } \\
\text { Reduced VLF } \\
\text { Reduced LF power } \\
\text { Reduced HF power }\end{array}$ & $\begin{array}{l}\text { Reduced VLF and ULF were predictive of cardiac } \\
\text { death }\end{array}$ \\
\hline Rubinger et al. (2009) & $\begin{array}{l}52 \text { ESRD patients on chronic HD therapy } \\
44 \text { ESRD patients with renal transplants } \\
41 \text { Healthy controls }\end{array}$ & $\begin{array}{l}\text { Reduced LF power } \\
\text { Reduced HF power }\end{array}$ & $\begin{array}{l}\text { LF power corrected } 1 \text { year following renal transplant } \\
\text { HF power not altered } 1 \text { year following renal transplant }\end{array}$ \\
\hline Furuland et al. (2008) & $\begin{array}{l}16 \text { Stage } 4 \text { CKD patients } \\
16 \text { Healthy controls }\end{array}$ & $\begin{array}{l}\text { Reduced SDNN } \\
\text { Reduced SDANN } \\
\text { No change in rMSSD } \\
\text { No change in pNN50 } \\
\text { Reduced total power } \\
\text { Reduced LF power } \\
\text { No change in HF power }\end{array}$ & $\begin{array}{l}\text { Hemoglobin normalization corrected reduction in LF } \\
\text { and total power } \\
\text { Hemoglobin normalization did not affect time domain } \\
\text { estimates of HRV }\end{array}$ \\
\hline Studinger et al. (2006) & $\begin{array}{l}14 \text { Juvenille ESRD patients on HD } \\
14 \text { Juvenille renal transplant recipients } \\
14 \text { Healthy controls }\end{array}$ & $\begin{array}{l}\text { Reduced RMSSD } \\
\text { Reduced LF power } \\
\text { No change in HF power }\end{array}$ & $\begin{array}{l}\text { Renal transplant recipients showed no difference in } \\
\text { RMSSD or HF power }\end{array}$ \\
\hline Steinberg et al. (1998) & $\begin{array}{l}66 \text { ESRD patients ( } 26 \text { diabetic) on HD } \\
33 \text { Healthy controls }\end{array}$ & $\begin{array}{l}\text { Reduced LF power } \\
\text { Reduced HF power }\end{array}$ & $\begin{array}{l}\text { Diabetes was a major determinant for reduced LF } \\
\text { power } \\
\text { Age was a borderline significant determinant for } \\
\text { reduced HF power }\end{array}$ \\
\hline Yamanaka et al. (2005) & $\begin{array}{l}27 \text { ESRD patients ( } 13 \text { diabetic) on HD } \\
46 \text { Healthy controls }\end{array}$ & $\begin{array}{l}\text { Reduced LF power } \\
\text { Reduced HF power }\end{array}$ & $\begin{array}{l}\text { LF and HF power was reduced further in diabetic } \\
\text { ESRD patients }\end{array}$ \\
\hline
\end{tabular}

\section{BAROREFLEX SENSITIVITY AND EFFECTIVENESS}

In comparisons to the numerous studies examining HRV in CKD/ESRD patients, relatively little is known regarding baroreceptor reflex control of HR. This may reflect the methodology required to investigate baroreceptor function, which requires a blood pressure recording as opposed to the simple acquisition of an ECG signal. It is not an indication, however, that assessing baroreceptor reflex function is not a useful marker of cardiac risk. On the contrary, reduced baroreceptor reflex control of HR has been established as a strong predictor of cardiac mortality following myocardial infarction (La Rovere et al., 1998), and in heart failure patients (Mortara and Tavazzi, 1996).

Baroreceptor reflex control of HR can be assessed by examining the sensitivity of the reflex (BRS), i.e., the ability of the 
baroreceptor reflex to produce reflex bradycardia or tachycardia. Alternatively, although not as utilized, the effectiveness of the baroreceptor reflex (BEI), i.e., how often the baroreceptor reflex produces a change in $\mathrm{HR}$ in response to a perturbation in blood pressure, can be examined (Di Rienzo et al., 2001). High BRS and BEI scores are reflective of healthy baroreceptor reflex control of HR.

Baroreceptor reflex control of HR, as examined by BRS (Pickering et al., 1972; Lazarus et al., 1973; Agarwal et al., 1991; Gerhardt et al., 1999; Gao et al., 2005; Studinger et al., 2006) and BEI (Johansson et al., 2005, 2007), is impaired in renal disease patients and may worsen as the disease severity increases. To date, only two studies (Bavanandan et al., 2005; Lacy et al., 2006) have examined BRS in moderate to severe non-diabetic CKD patients. Both studies showed that BRS was positively correlated to GFR, implying that BRS reduced as renal disease severity increases (i.e., GFR decreased). Furthermore, Lacy et al. (2006) demonstrated that BRS was lower in stage $4 \mathrm{CKD}$ patients compared with stage 3 CKD patients. However, neither study included a control group. Therefore, it is still unknown at which point in the disease process baroreceptor reflex control of HR alters. In addition to the impact of worsening renal function, additional co-morbidities may have additive negative effects on baroreceptor reflex function, with greater reductions in BRS and BEI noted in diabetic versus non-diabetic ESRD patients (Johansson et al., 2005).

The decline in BRS and BEI in ESRD can be reversed as conversion from chronic to nocturnal hemodialysis increases BRS and BEI (Chan et al., 2005, 2008). This is hypothesized to result from an increase in arterial compliance as the improvement in BRS that follows conversion to nocturnal hemodialysis is positively correlated with an increase in stroke volume to pulse pressure ratio (Chan et al., 2005). Furthermore, following renal transplantation, BRS and BEI is increased to control levels (Studinger et al., 2006; Rubinger et al., 2009).

The exact cause(s) of impaired baroreceptor reflex function in ESRD is unknown, but may relate, in part, to an inability for the

\section{REFERENCES}

Agarwal, A., Anand, I. S., Sakhuja, V., and Chugh, K. S. (1991). Effect of dialysis and renal transplantation on autonomic dysfunction in chronic renal failure. Kidney Int. 40, 489-495.

Bavanandan, S., Ajayi, S., Fentum, B., Paul, S. K., Carr, S. J., and Robinson, T. G. (2005). Cardiac baroreceptor sensitivity: a prognostic marker in predialysis chronic kidney disease patients[quest]. Kidney Int. 67, 1019-1027.

Brotman, D. J., Bash, L. D., Qayyum, R., Crews, D., Whitsel, E. A., Astor, B. C., and Coresh, J. (2010). Heart rate variability predicts ESRD and CKDrelated hospitalization. J. Am. Soc. Nephrol. 21, 1560-1570.

Burger, A. J., D'elia, J. A., Weinrauch, L. A., Lerman, I., and Gaur,

baroreceptors to sense changes in blood pressure. This could arise from vascular stiffness in the aortic arch and carotid sinus, the origin of baroreceptor afferents, as BRS is negatively correlated with increased carotid artery stiffness (Studinger et al., 2006) and an increase in vascular calcification, albeit in the superficial femoral artery, in dialysis patients (Chesterton et al., 2005). Alternatively, it could be due to abnormal central processing of the baroreceptor reflex or an inability for the cardiac vagal or sympathetic efferents to produce effective changes in HR.

Despite the limited number of studies examining BRS and $\mathrm{BEI}$ in ESRD patients, a reduction in these parameters confers an increased risk of mortality. Reduced BEI is an independent predictor of all-cause mortality, while reduced BRS, an independent predictor of sudden cardiac death (Johansson et al., 2007). The impact of reduced BRS in ESRD is not limited to a potential predisposition to life threatening arrhythmias. A reduction in BRS may also contribute to hemodialysis related hypotension, a significant cause of mortality in hemodialysis patients, due to an inability to counteract dialysis induced volume depletion (Heber et al., 1989; Chesterton et al., 2010). Further studies are required, however, to verify and strengthen the use of BRS as a predictive marker of an increased risk of cardiac mortality in CKD/ESRD.

\section{CONCLUSION}

Heart rate variability, BRS, and BEI are reduced in ESRD patients. These three parameters convey different information regarding cardiovascular health and may provide independent indications of a greater risk of cardiovascular mortality. Although individual HRV parameters are inconsistently reported as reduced in CKD/ESRD patients, a simple estimation of overall HRV (SDNN) can easily identify CKD/ESRD patients at risk of sudden cardiac death. Comparatively little is known regarding baroreceptor reflex function in CKD. Nevertheless, BRS and BEI have been shown to predict sudden cardiac death and all-cause mortality in ESRD patients respectively.

noradrenergic, and vascular effects of nocturnal home hemodialysis. Hypertension 42, 925-931.

Chan, C. T., Jain, V., Picton, P., Pierratos, A., and Floras, J. S. (2005). Nocturnal hemodialysis increases arterial baroreflex sensitivity and compliance and normalizes blood pressure of hypertensive patients with endstage renal disease. Kidney Int. 68, 338-344.

Chan, C. T., Shen, X. S., Picton, P., and Floras, J. (2008). Nocturnal home hemodialysis improves baroreflex effectiveness index of end-stage renal disease patients. $J$. Hypertens. 26, 1795-1800.

Chandra, P., Sands, R. L., Gillespie, B. W., Levin, N. W., Kotanko, P., Kiser, M., Finkelstein, F., Hinderliter, A., Pop-Busui, R., Rajagopalan, S., and Saran, R. (2011). Predictors of heart rate variability and its prognostic significance in chronic kidney disease. Nephrol. Dial. Transplant. doi: $10.1093 / \mathrm{ndt} / \mathrm{gfr} 340$

Chesterton, L. J., Selby, N. M., Burton, J. O., Fialova, J., Chan, C., and Mcintyre, C. W. (2010). Categorization of the hemodynamic response to hemodialysis: the importance of baroreflex sensitivity. Hemodial. Int. 14, 18-28.

Chesterton, L. J., Sigrist, M. K., Bennett, T., Taal, M. W., and Mcintyre, C. W. (2005). Reduced baroreflex sensitivity is associated with increased vascular calcification and arterial stiffness. Nephrol. Dial. Transplant. 20, 1140-1147.

Converse, R. L., Jacobsen, T. N., Toto, R. D., Jost, C. M. T., Cosentino, F., Fouad-Tarazi, F., and Victor, R. G. (1992). Sympathetic overactivity in 
patients with chronic renal failure. N. Eng. J. Med. 327, 1912-1918.

Di Rienzo, M., Parati, G., Castiglioni, P., Tordi, R., Mancia, G., and Pedotti, A. (2001). Baroreflex effectiveness index: an additional measure of baroreflex control of heart rate in daily life. Am. J. Physiol. Regul. Integr. Comp. Physiol. 280, R744-R751.

Efrati, S., Zaidenstein, R., Dishy, V., Beberashvili, I., Sharist, M., Averbukh, Z., Golik, A., and Weissgarten, J. (2002). ACE inhibitors and survival of hemodialysis patients. Am. J. Kidney Dis. 40, 1023-1029.

Fang, W., Oreopoulos, D. G., and Bargman, J. M. (2008). Use of ACE inhibitors or angiotensin receptor blockers and survival in patients on peritoneal dialysis. Nephrol. Dial. Transplant. 23, 3704-3710.

Fukuta, H., Hayano, J., Ishihara, S., Sakata, S., Mukai, S., Ohte, N., Ojika, K., Yagi, K., Matsumoto, H., Sohmiya, S., and Kimura, G. (2003a). Prognostic value of heart rate variability in patients with end-stage renal disease on chronic haemodialysis. Nephrol. Dial. Transplant. 18, 318-325.

Fukuta, H., Hayano, J., Ishihara, S., Sakata, S., Ohte, N., Takahashi, H., Yokoya, M., Toriyama, T., Kawahara, H., Yajima, K., Kobayashi, K., and Kimura, G. (2003b). Prognostic value of nonlinear heart rate dynamics in hemodialysis patients with coronary artery disease. Kidney Int. 64, 641-648.

Furuland, H., Linde, T., Englund, A., and Wikstrom, B. (2008). Heart rate variability is decreased in chronic kidney disease but may improve with hemoglobin normalization. J. Nephrol. 21, 45-52.

Gao, S. A., Johansson, M., Hammaren, A., Nordberg, M., and Friberg, P. (2005). Reproducibility of methods for assessing baroreflex sensitivity and temporal QT variability in endstage renal disease and healthy subjects. Clin. Auton. Res. 15, 21-28.

Gerhardt, U., Riedasch, M., Steinmetz, M., and Hohage, H. (1999). Kidney transplantation improves baroreceptor sensitivity. Int. J. Cardiol. 70, 233-239.

Giordano, M., Manzella, D., Paolisso, G., Caliendo, A., Varricchio, M., and Giordano, C. (2001). Differences in heart rate variability parameters during the post-dialytic period in type II diabetic and non-diabetic ESRD patients. Nephrol. Dial. Transplant. 16, 566-573.

Grassi, G., Quarti-Trevano, F., Seravalle, G., Arenare, F., Volpe, M., Furiani, S., Dell'oro, R., and Mancia, G. (2011).
Early sympathetic activation in the initial clinical stages of chronic renal failure. Hypertension 57, 846-851.

Grassi, G., Seravalle, G., Arenare, F., Buccianti, G., Furiani, S., Ilardo, V., Bolla G., and Mancia, G. (2009). Behaviour of regional adrenergic outflow in mild-to-moderate renal failure. $J$. Hypertens. 27, 562-566.

Guzik, P., Piskorski, J., Krauze, T., Schneider, R., Wesseling, K. H., Wykretowicz, A., and Wysocki, $\mathrm{H}$. (2007). Correlations between the Poincare plot and conventional heart rate variability parameters assessed during paced breathing. J. Physiol. Sci. 57, 63-71.

Hathaway, D. K., Cashion, A. K., Milstead, E. J., Winsett, R. P., Cowan, P. A., Wicks, M. N., and Gaber, A. O. (1998). Autonomic dysregulation in patients awaiting kidney transplantation. Am. J. Kidney Dis. 32, 221-229.

Hausberg, M., Kosch, M., Harmelink, P., Barenbrock, M., Hohage, H., Kisters, K., Dietl, K. H., and Rahn, K. H. (2002). Sympathetic nerve activity in end-stage renal disease. Circulation 106, 1974-1979.

Hayano, J., Takahashi, H., Toriyama, T., Mukai, S., Okada, A., Sakata, S., Yamada, A., Ohte, N., and Kawahara, H. (1999). Prognostic value of heart rate variability during long-term follow-up in chronic haemodialysis patients with end-stage renal disease. Nephrol. Dial. Transplant. 14, 1480-1488.

Heber, M. E., Lahiri, A., Thompson, D., and Raftery, E. B. (1989). Baroreceptor, not left ventricular, dysfunction is the cause of hemodialysis hypotension. Clin. Nephrol. 32, 79-86.

Herzog, C. A. (2003). Cardiac arrest in dialysis patients: approaches to alter an abysmal outcome. Kidney Int. 63, S197-S200.

Johansson, M., Gao, S. A., Friberg, P., Annerstedt, M., Bergstrom, G., Carlstrom, J., Ivarsson, T., Jensen, G., Ljungman, S., Mathillas, O., Nielsen, F.-D., and Strombom, U. (2005). Reduced baroreflex effectiveness index in hypertensive patients with chronic renal failure[ast]. Am. J. Hypertens. 18, 995-1000.

Johansson, M., Gao, S. A., Friberg, P., Annerstedt, M., Carlstrom, J., Ivarsson, T., Jensen, G., Ljungman, S., Mathillas, O., Nielsen, F. D., and Strombom, U. (2007). Baroreflex effectiveness index and baroreflex sensitivity predict all-cause mortality and sudden death in hypertensive patients with chronic renal failure. $J$. Hypertens. 25, 163-168.
Karnik, J. A., Young, B. S., Lew, N. L., Herget, M., Dubinsky, C., Lazarus, J. M., and Chertow, G. M. (2001). Cardiac arrest and sudden death in dialysis units. Kidney Int. 60, 350-357.

Kataoka, M., Ito, C., Sasaki, H., Yamane, K., and Kohno, N. (2004). Low heart rate variability is a risk factor for sudden cardiac death in type 2 diabetes. Diabetes Res. Clin. Pract. 64, 51-58.

Klein, I. H., Ligtenberg, G., Neumann, J., Oey, P. L., Koomans, H. A., and Blankestijn, P. J. (2003). Sympathetic nerve activity is inappropriately increased in chronic renal disease. J. Am. Soc. Nephrol. 14 3239-3244.

Kurata, C., Uehara, A., and Ishikawa, A. (2004). Improvement of cardiac sympathetic innervation by renal transplantation. J. Nucl. Med. 45, 1114-1120.

La Rovere, M. T., Bigger, J. T. Jr., Marcus, F. I., Mortara, A., and Schwartz, P. J. (1998). Baroreflex sensitivity and heart-rate variability in prediction of total cardiac mortality after myocardial infarction. ATRAMI (Autonomic Tone and Reflexes After Myocardial Infarction) Investigators. Lancet 351, 478-484.

La Rovere, M. T., Pinna, G. D., Hohnloser, S. H., Marcus, F. I., Mortara, A., Nohara, R., Bigger, J. T. Jr., Camm, A. J., and Schwartz, P. J. (2001). Baroreflex sensitivity and heart rate variability in the identification of patients at risk for life-threatening arrhythmias: implications for clinical trials. Circulation 103, 2072-2077.

La Rovere, M. T., Pinna, G. D., Maestri, R., Mortara, A., Capomolla, S. Febo, O., Ferrari, R., Franchini, M., Gnemmi, M., Opasich, C., Riccardi, P. G., Traversi, E., and Cobelli, F. (2003). Short-term heart rate variability strongly predicts sudden cardiac death in chronic heart failure patients. Circulation 107, 565-570.

Lacy, P., Carr, S. J., O'brien, D., Fentum, B., Williams, B., Paul, S. K., and Robinson, T. G. (2006). Reduced glomerular filtration rate in predialysis non-diabetic chronic kidney disease patients is associated with impaired baroreceptor sensitivity and reduced vascular compliance. Clin. Sci. 110, 101-108.

Lazarus, J. M., Hampers, C. L., Lowrie, E. G., and Merrill, J. P. (1973). Baroreceptor activity in normotensive and hypertensive uremic patients. Circulation 47, 1015-1021.

Molgaard, H., Sorensen, K. E., and Bjerregaard, P. (1991). Attenuated 24-h heart rate variability in apparently healthy subjects, subsequently suffering sudden cardiac death. Clin. Auton. Res. 1, 233-237.

Mortara, A., and Tavazzi, L. (1996). Prognostic implications of autonomic nervous system analysis in chronic heart failure: role of heart rate variability and baroreflex sensitivity. Arch. Gerontol. Geriatr. 23, 265-275.

Mylonopoulou, M., Tentolouris, N., Antonopoulos, S., Mikros, S., Katsaros, K., Melidonis, A., Sevastos, N., and Katsilambros, N. (2010). Heart rate variability in advanced chronic kidney disease with or without diabetes: midterm effects of the initiation of chronic haemodialysis therapy. Nephrol. Dial. Transplant. 25, 3749-3754.

Parfrey, P. S., and Foley, R. N. (1999). The clinical epidemiology of cardiac disease in chronic renal failure. $J$. Am. Soc. Nephrol. 10, 1606-1615.

Parisotto, V., Lima, E. M., Silva, J. M., De Sousa, M. R., and Ribeiro, A. L. (2008). Cardiac sympathetic dysautonomia in children with chronic kidney disease. J. Nucl. Cardiol. 15, 246-254.

Park, J., Campese, V. M., Nobakht, N. and Middlekauff, H. R. (2008). Differential distribution of muscle and skin sympathetic nerve activity in patients with end-stage renal disease. J. Appl. Physiol. 105, 1873-1876.

Pickering, T. G., Gribbin, B., and Oliver, D. O. (1972). Baroreflex sensitivity in patients on long-term haemodialysis. Clin. Sci. 43, 645-657.

Pun, P. H., Smarz, T. R., Honeycutt, E. F., Shaw, L. K., Al-Khatib, S. M., and Middleton, J. P. (2009). Chronic kidney disease is associated with increased risk of sudden cardiac death among patients with coronary artery disease. Kidney Int. 76, 652-658.

Roumelioti, M. E., Ranpuria, R., Hall, M., Hotchkiss, J. R., Chan, C. T., Unruh, M. L., and Argyropoulos, C. (2010). Abnormal nocturnal heart rate variability response among chronic kidney disease and dialysis patients during wakefulness and sleep. Nephrol. Dial. Transplant. 25, 3733-3741.

Rubinger, D., Backenroth, R., and Sapoznikov, D. (2009). Restoration of baroreflex function in patients with end-stage renal disease after renal transplantation. Nephrol. Dial. Transplant. 24, 1305-1313.

Sahin, M., Kayatas, M., Urun, Y., Sennaroglu, E., and Akdur, S. (2006). Performing only one cardiovascular reflex test has a high positive predictive value for diagnosing autonomic 
neuropathy in patients with chronic renal failure on hemodialysis. Ren. Fail. 28, 383-387.

Schwartz, P. J., La Rovere, M. T., and Vanoli, E. (1992). Autonomic nervous system and sudden cardiac death. Experimental basis and clinical observations for post-myocardial infarction risk stratification. Circulation 85, I77-I91.

Schwartz, P. J., and Stone, H. L. (1980). Left stellectomy in the prevention of ventricular fibrillation caused by acute myocardial ischemia in conscious dogs with anterior myocardial infarction. Circulation 62, 1256-1265.

Schwartz, P. J., Vanoli, E., StrambaBadiale, M., De Ferrari, G. M., Billman, G. E., and Foreman, R. D. (1988). Autonomic mechanisms and sudden death. New insights from analysis of baroreceptor reflexes in conscious dogs with and without a myocardial infarction. Circulation 78, 969-979.

Shamseddin, M. K., and Parfrey, P. S. (2011). Sudden cardiac death in chronic kidney disease: epidemiology and prevention. Nat. Rev. Nephrol. 7, 145-154.
Stauss, H. M. (2003). Heart rate variability. Am. J. Physiol. Regul. Integr. Comp. Physiol. 285, R927-R931.

Steinberg, A. A., Mars, R. L., Goldman, D. S., and Percy, R. F. (1998). Effect of end-stage renal disease on decreased heart rate variability. Am. J. Cardiol. 82, 1156-1158, A1110.

Studinger, P., Lenard, Z., Mersich, B., Reusz, G. S., and Kollai, M. (2006). Determinants of baroreflex function in juvenile end-stage renal disease. Kidney Int. 69, 2236-2242.

Task Force of the ESC and NASPE. (1996). Heart rate variability: standards of measurement, physiological interpretation and clinical use. Circulation 93, 1043-1065.

Tong, Y. Q., and Hou, H. M. (2007). Alteration of heart rate variability parameters in nondiabetic hemodialysis patients. Am. J. Nephrol. 27, 63-69.

U.S. Renal Data System. (2011). USRDS 2011 Annual Data Report: Atlas of Chronic Kidney Disease and EndStage Renal Disease in the United States. Bethesda, MD: National Institutes of Health, National Institute of Diabetes and Digestive and Kidney Diseases.
Yamanaka, N., Aoyama, T., Ikeda, N., Higashihara, M., and Kamata, K. (2005). Characteristics of heart rate variability entropy and blood pressure during hemodialysis in patients with end-stage renal disease. Hemodial. Int. 9, 303-308.

Yang, Y. W., Wu, C. H., Tsai, M. K., Kuo, T. B., Yang, C. C., and Lee, P. H. (2010). Heart rate variability during hemodialysis and following renal transplantation. Transplant. Proc. 42, 1637-1640.

Yildiz, A., Sever, M. S., Demirel, S. Akkaya, V., Turk, S., Turkmen, A., Ecder, T., and Ark, E. (1998). Improvement of uremic autonomic dysfunction after renal transplantation: a heart rate variability study. Nephron 80, 57-60.

Zaza, A., and Lombardi, F. (2001). Autonomic indexes based on the analysis of heart rate variability: a view from the sinus node. Cardiovasc. Res. 50 434-442.

Zoccali, C., Mallamaci, F., Parlongo, S., Cutrupi, S., Benedetto, F. A., Tripepi, G., Bonanno, G., Rapisarda, F., Fatuzzo, P., Seminara, G., Cataliotti, A., Stancanelli, B., and Malatino, L. S. (2002). Plasma norepinephrine predicts survival and incident cardiovascular events in patients with end-stage renal disease. Circulation 105, 1354-1359.

Conflict of Interest Statement: The author declares that the research was conducted in the absence of any commercial or financial relationships that could be construed as a potential conflict of interest.

Received: 30 October 2011; paper pending published: 17 November 2011; accepted: 20 December 2011; published online: 12 January 2012.

Citation: Hildreth CM (2012) Prognostic indicators of cardiovascular risk in renal disease. Front. Physio. 2:121. doi: 10.3389/fphys.2011.00121

This article was submitted to Frontiers in Integrative Physiology, a specialty of Frontiers in Physiology.

Copyright (c) 2012 Hildreth. This is an open-access article distributed under the terms of the Creative Commons Attribution Non Commercial License, which permits non-commercial use, distribution, and reproduction in other forums, provided the original authors and source are credited. 